\title{
DISINTEGRATION OF COSMIC GARBAGE PARTICLES BY ELECTRON BEAMS
}

\author{
V.V.VLADIMIROV, V.N.GORSHKOV \\ Physics Institute, Ukrainian National Academy of Sciences, \\ 46 Nauki Av., 252650 Kiev DSP, Ukraine
}

Received September 12, 1995

\begin{abstract}
It has been shown that at charging and melting of the cosmic garbage particles by electron beam their intensive disintegration into very small droplets, which are $10^{2}-10^{4}$ times less as small as an original drop, is possible. This process occurs only in the case, when the particle charge significantly exceeds the Rayleigh limit, determining the instability threshold for a charged drop. The consideration was carried out for garbage particles, having dimensions $0.1-1 \mathrm{~cm}$. At the solution of this problem we have taken into account the compensating ion current, coming from the cosmic plasma to the negatively charged particle surface.
\end{abstract}

\section{Introduction}

At the end of the 19-th century Rayleigh carried out classical works devoted to the investigation of cylindrical liquid jet instability [1] and strongly charged drop [2,3]. These works have become the scientific basis [4] for development of the important technological branches, connected with small liquid drops generation. Let us mention that the theory of charged drop instability $[2,3]$ was used in droplet nucleus model for explanation of uranium nucleus fission. In this work the possibility of the Rayleigh results [1-3] application in cosmic researches have been considered. The first one is connected with termination of small particles of cosmic garbage by using electron beams, which charge and melt these particles.

At a rather high drop charge which significantly exceeds the Rayleigh limit, its intensive disintegration into very small droplets occurs. In fact, the original cosmic garbage particle (GP) transforms into dust. Let us point out that as a result of cosmic researches a great amount of garbage fragments has been accumulated in cosmos. Some of them have been formed as a result of planned (and nonplanned) explosions of cosmic objects, others due to the collisions of the garbage fragments with each other. According to data in 1992 [5] about $4 \cdot 10^{6}$ garbage fragments, having dimension more than $10 \mathrm{~cm}$ have been piled up. The amount of smaller fragments (with dimensions 0.1-1 cm) has not been measured and approximately makes up $99 \%$ of the total number of garbage fragments [5,6]. These particles, having high velocity $\left(10^{6} \mathrm{~cm} / \mathrm{s}\right)$, are able to perforate space ship body and astronaut space suit. The problem, considered below, devoted just to the problem of termination of these small particles. At rather high drop charge $q>q_{c r}[2,3]$ the instability, which leads to the drop deformation (and decay) 
due to the spherical harmonic excitation $(l=2)$ on its surface, appears. At supercritical drop charge $q \gg q_{c r}$ very high harmonics $l \gg 2$ are excited and the jet palisade appears on melted surface of the GP (figure 1). These jets decay into very small drops at the development of the jet sausage instability (SI) [1]. This phenomenon also was predicted by Rayleigh [3], but its theory was not created. We have shown that it is just supercritical charge of the original GP that leads to its quick decay into very small droplets, having dimensions $10^{2}-10^{4}$ times as small as the dimension of initial GP. These microdroplets are not dangerous for space crafts and astronauts. In essence, it would be possible to use the electron-beam weapon, created on the program "Star wars" for struggle with cosmic garbage. As Bible says: "Let us beat the sword on the plough".

It is necessary to point out that at the solution of the task mentioned above one should take into account the influence of cosmic plasma on the charging process of GP. This influence is extremely essential and connected with coming of compensating ion current from surrounding space plasma to negatively charged surface of GP - figure 1 . The value of this current is proportional to the plasma density and thus strongly depends upon trajectory height of an object. At the calculation of ion current we have used the results of Langmuir and Mott-Smith [7], which is devoted to the theory of ion spherical probes in the gas discharge plasmas.

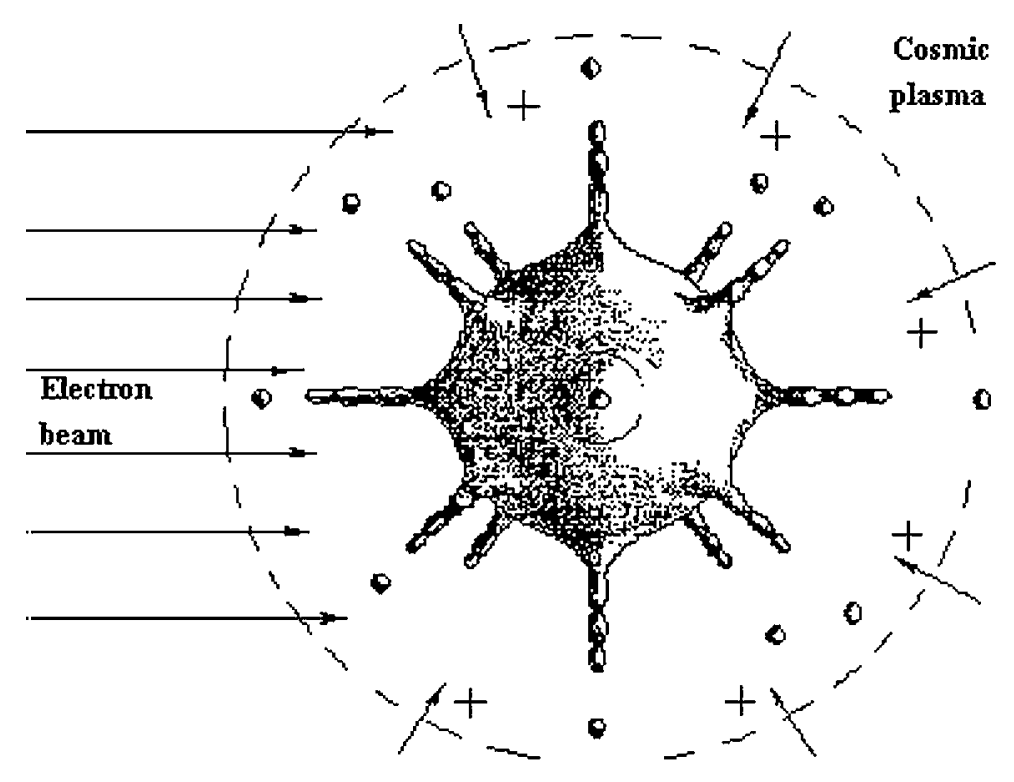

Figure 1. The star of Rayleigh (1882) in cosmos.

\section{The Disintegration of cosmic garbage particles by elec- tron beam}

It is supposed that a cosmic GP is melted and charged by impulse electron beam, so that the GP is a strongly charged drop $\left(q \gg q_{c r}\right)$ before the beginning of microdroplet decay. 
It is known [2,3] that while the charge of a conductive drop $q>q_{c r}=$ $\sqrt{16 \pi \sigma R^{3}}$, where $R$ is the drop radius, $\sigma$ is the surface tension coefficient, and when the electric field $E>E_{c r}=q_{c r} / R^{2}=\sqrt{\frac{16 \pi \sigma}{R}}$ appears on its surface, the instability occurs. The growth rate $\gamma$ of this instability in case of small viscosity is determined by the expression [3]:

$$
\gamma=2 \omega_{c} \sqrt{l(l-1)\left(\varepsilon^{2}-\frac{l+2}{4}\right)},
$$

where $l$ is the spherical harmonic number, $\varepsilon=E / E_{c r}=q / q_{c r}, \omega_{c}=\sqrt{\frac{\sigma}{\rho R^{3}}}$, $\rho$ is the liquid density.

At $\varepsilon>1$ the harmonic $l=2$ is excited and the drop transforms into spheroid [8] and two thin jets are injected from its top [4,8]. When these jets decay owing to SI [1], a cascade of very small charged drops is emitted. At the same time only a small part of the original drop mass $(M)$ is lost [9]. That is why the process of the GP disintegration is not effective at $\varepsilon \approx 1$.

Below for the first time the process of microdroplet decay (MD) of the original GP drop at $\varepsilon \gg 1$, which has the following peculiarities, is considered:

a) If $\varepsilon \gg 1$, according to (1) maximum value of $\gamma$ corresponds to high number harmonics $(l \gg 2)$ and as a result the jet palisade, from the top of which the drops are emitted, is formed on the entire surface of molten GP. This phenomenon was first mentioned by Rayleigh [3]. At the same time the original drop keeps its spherical form and looks like a "hedgehog". We called this phenomenon "The Rayleigh star" as is shown in figure 1.

b). It is assumed that GP drop is continuously charged by electron beam in the MD process, that allows to compensate the charge expense.

It is just multijet mechanism MD and GP drop continuous charging that makes possible to realize its intensive disintegration at $\varepsilon \gg 1$.

The maximum value of $\gamma$ according equation (1) at $\varepsilon \gg 1$ corresponds to the value $l=l_{m=8} 8 \varepsilon^{2} / 3 \gg 1$, an appropriate wavelength $\lambda_{m}=2 \pi R / l_{m}=$ $3 \pi R /\left(4 \varepsilon^{2}\right)$ and a jet number on the drop surface:

$$
N_{j}=4 \pi R^{2} \lambda_{m}^{-2}=64 \varepsilon^{4} /(9 \pi) .
$$

At $\varepsilon=10$, according to equation (2) $N_{j}=2.26 \cdot 10^{4}$, that is a great number of jets are aroused on GP drop surface.

Approximation of small viscosity [10]: $\gamma_{m} \gg 2 \nu l_{m}^{2} / R^{2}$, where $\nu$ - is the kinematic viscosity coefficient, $\gamma_{m}=\gamma\left(l_{m}\right)=16 \omega_{c} \varepsilon^{3} /(3 \sqrt{3})$, is fulfilled, if:

$$
\varepsilon \ll \sigma \sqrt{\frac{3 \pi}{\rho}} \frac{1}{2 \nu E_{c r}} .
$$

For example, choosing parameters, which correspond to the stainless steel melt- $\rho=8 \mathrm{~g} / \mathrm{cm}^{3}, \nu=2 \cdot 10^{3} \mathrm{~cm}^{2} / \mathrm{s}, \sigma=1.8 \mathrm{~J} / \mathrm{m}^{2}$ and $R=0.05$ $\mathrm{cm}\left(E_{c r}=4 \cdot 10^{5} \mathrm{~V} / \mathrm{cm}\right)$, criterium (3) is fulfilled, if $\varepsilon \ll 300$. All further estimations will be made at parameter values mentioned above.

At $\varepsilon=10$ drop potential is $\varphi=E R=\varepsilon E_{c r} R=200 \mathrm{kV}$. That is why beam electrons must have high energy $\left(E_{b}>e \varphi\right)$ so that the beam cut-off does not take place.

Let us consider the charging process of GP in space by electron beam taking into account the compensating ion current coming from the cosmic 
plasma (figure 1) into the GP surface. This process is described by the equation:

$$
\frac{d q}{d t}=I_{e}-I_{i}
$$

where $I_{e}=2 \pi R^{2} j_{e}$ is the electron current onto GP surface, $j_{e}$ is the beam current density, and $I_{i}$ is the ion current $[7,11]$ :

$$
I_{i}=\frac{4 \pi R^{2} e \varphi j_{B}}{k T_{i}},
$$

where $j_{B}=0.61 e n_{p} \sqrt{k T_{e} / M_{i}}$ is the density of ion current from the plasma border (Bohm current [11]); $T_{e}, T_{i}$ is the electron and ion temperature of the cosmic plasma, $n_{p}$ is the plasma density, $M_{i}$ is the ion mass, $k$ is the Boltzmann constant, $e$ is the electron charge.

According to (4), (5) while GP is being charged by electron beam, the value $\varphi(\varphi=q / R)$ is increasing, value $I_{i}$ is growing also and at $I_{i}=I_{e}$ the stationary value $\varphi=\varphi_{s}$ is set up:

$$
\varphi_{s}=\frac{j_{e}}{j_{B}} \frac{k T_{i}}{2 e}
$$

and:

$$
\varepsilon=\frac{\varphi_{s}}{R E_{c r}}=\frac{j_{e}}{8 j_{B}} \frac{k T_{i}}{e \sqrt{\pi \sigma R}}
$$

According to (4), (5) the characteristic time of the stationary state set up is determined by:

$$
\tau_{s}=k T_{i} /\left(4 \pi e R j_{B}\right) .
$$

Let us make numerical estimations in case, when trajectory height of GP is $H=500 \mathrm{~km}$. At this height the hydrogen ions dominate, $n_{p}=10^{6} \mathrm{~cm}^{-3}$, $k T_{e}=0.3 \mathrm{eV}, k T_{i}=0.1 \mathrm{eV}, j_{B}=5.37 \cdot 10^{-8} \mathrm{~A} / \mathrm{cm}^{2}$.

In accordance with (6), (8) the value $\varphi_{s}=200 \mathrm{kV}(\varepsilon=10, R=0.05$ $\mathrm{cm})$ is set up at $j_{e}=0.2 \mathrm{~A} / \mathrm{cm}^{2}, \tau_{s}=3 \cdot 10^{-6} \mathrm{~s}$.

The time of GP entire melting is determined by:

$$
\tau_{m}=\frac{2 e R}{3 E_{b} j_{e}}(c \rho \Delta T+Q),
$$

where $c=0.5 \frac{\mathrm{J}}{\operatorname{deg} \cdot g}$ is specific heat, $Q=1.9 \cdot 10^{3} \mathrm{~J} / \mathrm{cm}^{3}$ is the unit volume latent heat, $\Delta T=T_{m}-T_{0} \approx 1.6 \cdot 10^{3} \mathrm{deg}$., $T_{m}$ and $T_{0}$ is the melting and initial temperature of the GP.

According to (9) $\tau_{m}=10^{-3} \mathrm{~s}$, if $E_{b}=600 \mathrm{keV}, j_{e}=0.2 \mathrm{~A} / \mathrm{cm}^{2}$. By this means that the process of GP melting is the most continuous. At first GP charging takes place, then melting occurs. When the GP velocity is $10^{6} \mathrm{~cm} / \mathrm{s}$, it should be irradiated by electron beam on the trajectory length $\approx 10 \mathrm{~m}$ for the entire melting. The electron beam follows the GP, the beam power $P=I_{e} E_{b} / e \approx 2 \cdot 10^{3} \mathrm{~W}$.

At height $H=10^{3} \mathrm{~km}$ the plasma density strongly decreases $\left(n_{p}=\right.$ $10^{4} \mathrm{~cm}^{-3}$ ), the value $j_{B}=5.37 \cdot 10^{-10} \mathrm{~A} / \mathrm{cm}^{2}$ and in accordance with (7) the magnitude $j_{e}$ should be decreased by two orders to accomplish the value $\varepsilon=10$. In conformity with that the time of melting (9) increases up to the 
value $\tau_{m}=0.1 \mathrm{~s}$ (at the same value $E_{b}=600 \mathrm{keV}$ ) and this regime is unreal in space. More real regime is the one when $\varepsilon=100\left(j_{e}=0.02 \mathrm{~A} / \mathrm{cm}^{2}\right), \varphi_{s}=$ $2 M V$ and $E_{b}=6 M e V$. In this case $\tau_{m}=10^{-3} s$. As this takes place, the process of GP disintegration is realized much faster due to the big value of $\varepsilon$.

Analogous estimations can by made for GP with $R=0.5 \mathrm{~cm}$. In this case the value $\varepsilon=10$ is accomplished $(H=500 \mathrm{~km})$ if $j_{e}=0.6 \mathrm{~A} / \mathrm{cm}^{2}$.

At the same time it is necessary the electron energy to be higher $E_{b}=$ $2 \mathrm{MeV}$, because $\varphi_{s}=600 \mathrm{kV}$. In this case $\tau_{m}=10^{-3} \mathrm{~s}, P \approx 2 \cdot 10^{6} \mathrm{~W}$.

At height $H=10^{3} \mathrm{~km}$ it is necessary to use the regime $\varepsilon=100\left(j_{e}=\right.$ $\left.0.06 \mathrm{~A} / \mathrm{cm}^{2}\right), \varphi_{s}=6 \mathrm{MV}$ and $E_{b}=10 \mathrm{MeV}$. begin.

After charging and melting of GP the process of microdroplet decay

To determine the characteristics of ME it is necessary to calculate the jet parameters (height $h$, radius $r_{0}$, velocity $v_{0}$ ). It is considered that the jets are identical and have cylindrical form with semispherical top. The equations for mass and impulse conservation of jet have the appearance:

$$
\pi r_{0}^{2} \rho v_{0}=M_{d} / \tau, \quad \pi r_{0}^{2}\left(\frac{E_{j}^{2}}{8 \pi}-\frac{2 \sigma}{r_{0}}\right)=M_{d} v_{0} / \tau,
$$

where $M_{d}=\pi r_{0}^{2} \lambda_{R} \rho$ is the mass of tearing off droplet; $\lambda_{R} \approx 9 r_{0}$ is the wavelength, which corresponds to the growth rate maximum $\left(\gamma_{R}\right)$ of SI [1]; $E_{j}$ is the field on the jet top; $\tau=\gamma_{R}^{-1} \ln \left(r_{0} / \zeta_{0}\right)$ is the characteristic time of SI development, $\zeta_{0}$ is the amplitude of initial fluctuations of the surface radial displacements; $\gamma_{R}=0.34 r_{0}^{-3 / 2} \sqrt{\sigma / \rho}[1]$ in the case of small viscosity.

In further we shall suppose that $\zeta_{0} / r_{0}=10^{-2}$ and $\tau=4.6 / \gamma_{R}$. Using the equation (10) it is possible to obtain:

$$
\lambda_{R}=v_{0} \tau, \quad v_{0}=\frac{E_{j}}{\sqrt{8 \pi \rho}} \sqrt{1-\frac{R}{r_{0}} \frac{E_{c r}^{2}}{E_{j}^{2}}} .
$$

As value $v_{0} \tau$ determines the length of nondestroyed jet part, the SI development with wavelength $\lambda_{R}$ takes place, if $h=2 \lambda_{R}=18 r_{0}$.

Using the condition of surface equipotentiality of GP drop ("Rayleigh star"):

$$
\left(q-N_{j} q_{0}\right) / R=q_{0} / r_{0+}\left(q-N_{j} q_{0}\right) /(R+h),
$$

where $q_{0}$ is the charge of the jet top, it is easy to derive in case $h \ll R$ :

$$
E_{j}=q_{0} / r_{0}^{2}=\frac{h}{r_{0}} \frac{E}{1+N_{j} h r_{0} / R^{2}}=\frac{18 E}{1+128 x^{2} / \pi},
$$

where $x=r_{0} \varepsilon^{2} / R$.

Using (11), (13) it is possible to obtain the equation for the jet radius:

$$
38.2 x^{1 / 2}\left[1-\left(1+128 x^{2} / \pi\right)^{2} /(324 x)\right]^{1 / 2}=1+128 x^{2} / \pi .
$$

This equation has two real roots : $x_{1}=0.51$ and $x_{2}=3.7 \cdot 10^{-3}$. The root $x_{2}$ does not satisfy the small viscosity criterium $\left(\tau \ll r_{0}^{2} / \nu\right)$, which used at the receiving (14). So the jet radius at $\varepsilon \gg 1$ is determined by:

$$
r_{0}=0.51 R / \varepsilon^{2} \text {. }
$$


Taking into consideration (11), (13), (15) it is possible to calculate all jet and microdroplet parameters:

$$
\begin{gathered}
h=9.2 R / \varepsilon^{2}, \quad E_{j}=1.55 E_{c r} \varepsilon, \quad v_{0}=\varepsilon \omega_{c} R, \\
M_{d} / M \approx \varepsilon^{-6}, \quad q_{d} / q=0.4 \varepsilon^{-4}, \quad R_{d}=1.9 r_{0} \approx R / \varepsilon^{2},
\end{gathered}
$$

and also to calculate the consumption of GP mass:

$$
\frac{d M}{d t}=-N_{j} M_{d} / \tau=-M \varepsilon \omega_{c}
$$

The radius of the initial drop diminishes at MD process.

The mass consumption is equal to $0.9 M$ fulfilled during the time: $\tau_{M}=$ $1.1 /\left(\varepsilon \omega_{c}\right)$. If $R=0.05 \mathrm{~cm}\left(\omega_{c}=1.34 \cdot 10^{3} \mathrm{~s}^{-1}\right)$, then at $\varepsilon=10, \tau_{M}=7 \cdot 10^{-5} \mathrm{~s}$. In the case $R=0.5 \mathrm{~cm}\left(\omega_{c}=42.4 \mathrm{~s}^{-1}\right) \tau_{M}=2 \cdot 10^{-3} \mathrm{~s}$.

So after GP melting the "electric explosion" of Rayleigh star, accompanied by the formation of very small droplets, occurs. According to (17) the droplet radius is: $R_{d}=\left(10^{-2}-10^{-4}\right) R$ at $\varepsilon=10-100$.

\section{Conclusions}

We have shown that a number of classical results, obtained by Rayleigh [1-3], may be used for solution of some space problems. The problem, connected with termination of small particles of cosmic garbage by electron beams, seems to be important because these particles (with dimensions $0.1-1 \mathrm{~cm}$ ) are dangerous for astronauts and satellites.

Let us point out that at the solution of this problem it's necessary to take into account the ion current, coming from the cosmic plasma to the negatively charged surface of cosmic object. The value of this current depends upon the trajectory height.

\section{Acknowledgments}

This research has been supported in part by International Science Foundation (Soros's Foundation) under grant N 66200. Authors express gratitude to this foundation.

\section{References}

[1] Lord Rayleigh. On the instability of jets. // Proc. London Math. Soc., 1878, vol. 10 , p. $4-26$.

[2] Lord Rayleigh. On the capillary phenomena of jets. // Proc. R. Soc. London, 1879, vol. 29, p. 71-97.

[3] Lord Rayleigh. On the equilibrium of liquid conducting masses charged with electricity. // Phil. Mag., 1882, vol. 14, p. 184-186.

[4] Bailey A.G. Electrostatic atomization of liquids. // Sci. Prog. Oxf., 1974, vol. 61 , p. 555-581.

[5] Grinberg E.I. Cosmos pollution and cosmic flights. // Nature (Russia), 1992, No 8, p. 12-17.

[6] Eichler P., Rex D. Debris chain reactions. AIAA Pap., 1990, No 1365, p. 9-24; Eichler P., Bade A. Removal of debris from orbit. Ibid., 1990, No 1366 , p. 8-25. 
[7] Mott-Smith H., Langmuir I. The theory of collectors in gaseous discharges. // Phys. Rev., 1926, vol. 28, No 4, p. 727-763.

[8] Taylor G.I. Disintegration of water drops in an electric field. // Proc. R. Soc. London, 1964, vol. A280, No 1382, p. 383-397.

[9] Schweizer J.W., Hanson D.N. Stability limit of charged drops. // J. Coll. Int. Sci., 1971, vol. 35, No 3, p. 417-423.

[10] Landau L.D., Lifshitz E.M. Hydrodynamics. Moscow, Nauka, 1988.

[11] Allen J.E., Boyd R.L.F., Reynolds P. The collection of positive ions by a probe immersed in a plasma. // Proc. of the Phys. Soc., 1957, vol. B70, No 447B, p. 297-304.

\title{
ПОДРІБНЕННЯ ЕЛЕМЕНТІВ КОСМІЧНОГО СМІТТЯ ЕЛЕКТРОННИМИ ПУЧКАМИ
}

\author{
В.В.Владіміров, В.Н.Горшков
}

Показано, що при заряджуванні та розплавленні елементів космічного сміття електронними пучками можливий їх інтенсивний розклад на дуже малі краплини, розмір яких в $10^{2}-10^{4}$ раз менший, ніж розміри початкових частинок. Цей процес виникає лише у тому випадку, коли заряд частинки суттєво перевищує межу Релея, визначаючи поріг нестабільності для зарядженої краплі. Розгляд проведено для елементів сміття 3 розміром 0.1-1 см. При розв'язку цієї проблеми ми прийняли до уваги потік компенсаційних іонів 3 космічної плазми на негативно заряджену поверхню частинки. 